\title{
No Conventional Fluid Film Bearings with Waved Surface
}

\author{
Florin Dimofte, Nicoleta M. Ene and Abdollah A. Afjeh \\ The University of Toledo \\ USA
}

\section{Introduction}

A new type of fluid film bearings called "wave bearing" has been developed since 1990's by Dimofte (Dimofte, 1995 a; Dimofte, 1995 b). The main characteristic of the wave bearings is that they have a continuous wave profile on the stationary part of the bearing.

The wave bearings can be designed as journal bearings to support radial loads or as thrust bearings for axial loads. One of the main advantages of the wave bearings is that they are very simple and easy to manufacture. In most cases they have only two parts. A journal bearing consists of a shaft and a sleeve while a thrust bearing consists of a stationary and a rotating disk. One of the bearing parts is sometimes incorporated into the machine part that is supported by the bearing. For example, the wave bearing can be used to support the gear of a planetary transmission, the bearing sleeve being incorporated into the gear (Dimofte et al., 2000).

Compressible (gases) or incompressible (liquids) fluids can be used as lubricants for both the journal and thrust wave bearings. Tests were conducted with liquid lubricants (synthetic turbine oil, perfluoropolyethers -PFPE-K) and air on dedicated test rigs installed in NASA Glenn Research Centre in Cleveland, OH USA (Dimofte et al., 2000; Dimofte et al., 2005). In this chapter, the wave bearings lubricated with incompressible fluids, commonly known as fluid film wave bearings, are analysed. The performance of both journal and thrust bearings is examined. Because one of the most important properties of the wave journal bearings compared to other types of journal bearings is their improved stability, the first part of the chapter is dedicated to the study of the dynamic behaviour of the journal wave bearings. The wave thrust bearings can be used for axially positioning the rotor or to carry a thrust load. For this reason, the steady-state performance of the thrust wave bearings is analysed in the second part of the chapter.

\section{The journal wave bearing concept}

For a journal bearing, if the shaft rotates and the sleeve is stationary, then the wave profile is superimposed on the inner diameter of the sleeve. To exemplify the concept, a comparison between a wave bearing having circumscribed a three-wave profile on the inner diameter of the sleeve and a plain journal bearing is presented in Fig. 1. In Fig. 1, the wave amplitude and the clearance between the shaft and the sleeve are greatly exaggerated to better visualize the geometry. Actually, the clearance is around a thousandth of the diameter and the wave amplitude is less than one half of the clearance. 


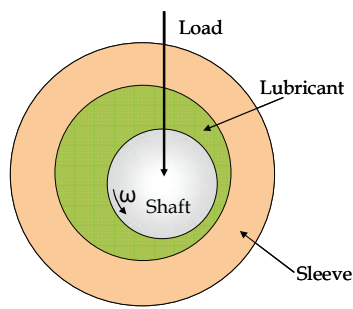

Plain journal bearing

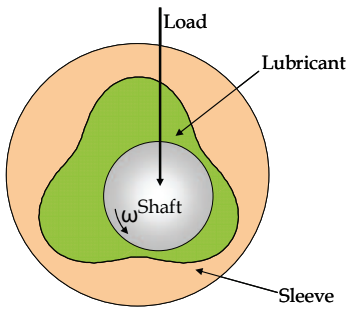

Three-wave journal bearing

Fig. 1. Comparison between the wave journal bearing and the plain journal bearing

Because the geometry of the wave bearing is very close to the geometry of the plain circular bearing, the load capacity of the wave bearing is close to that of the plain journal bearing and superior to the load capacity of other types of journal fluid bearings. In fact, due to their improved thermal stability, the wave journal bearings can actually carry more load than the plain bearings. The wave bearing concept solves two problems encountered by plain fluid film bearings by stabilizing the shaft (Ene et al., 2008, a) and by giving enhanced stiffness to the bearing (Dimofte, 1995, a). The wave bearings have also important damping properties. They attenuate the vibration of the rotor. Consequently, the additional fluid damping system, usually required when other types of bearings are used to support the shaft, can be eliminated. Due to their damping properties, the wave bearings can be also used to attenuate the noise generated by the gear mesh in a geared transmission (Dimofte \& Ene, 2009). The geometrical parameters of a journal wave bearing can be seen in Fig. 2.

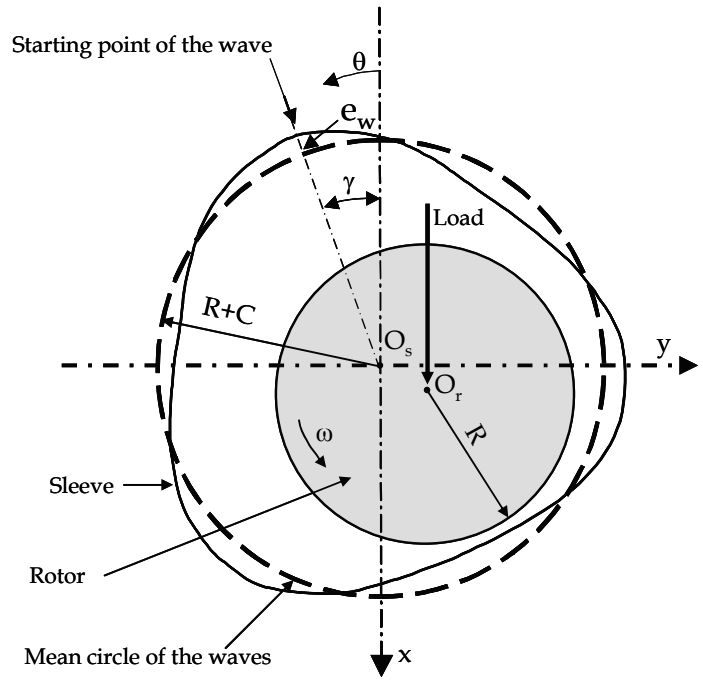

Fig. 2. The geometry of a wave journal bearing

The radial clearance $C$ of the wave bearing is defined as the difference between the radius of the mean circle of the waves, $R_{\text {med, }}$ and the radius, $R$, of the shaft:

$$
\mathrm{C}=\mathrm{R}_{\text {med }}-\mathrm{R}
$$


The radial clearance is usually around one thousandth of the journal radius. For computational purposes, the wave amplitude is usually non-dimensionalised by dividing it by the radial clearance:

$$
\varepsilon_{\mathrm{w}}=\frac{\mathrm{e}_{\mathrm{w}}}{\mathrm{C}}
$$

The ratio $\varepsilon_{W}$ is generally called the wave amplitude ratio. The wave amplitude ratio is one of the most important geometrical characteristics of a wave bearing because the performance of the wave bearing is strongly influenced by this ratio (Ene et all., 2008 a). The value of the wave amplitude ratio is usually smaller than 0.5.

The performance of a wave journal bearing also depends on the number of the waves, $\mathrm{n}_{\mathrm{w}}$, and on the wave position angle, $\gamma$. The wave position angle is defined as the angle between the starting point of the waves (one of the points where the wave has maximum value) and the load, W (see Fig. 2). Theoretical and experimental studies indicate that the best performance is obtained for a bearing with three waves and a zero wave position angle. (Dimofte, 1995 a; Dimofte, 1995 b).

The load capacity of a wave bearing is due to the rotation of the shaft and to the variation of film thickness along the circumference. In a system of reference $\mathrm{O}_{\mathrm{S} x y}$ fixed with respect to the sleeve (Fig. 2), the film thickness is given by:

$$
\mathrm{h}=\mathrm{C}+\mathrm{x} \cos \theta+\mathrm{y} \sin \theta+\mathrm{e}_{\mathrm{w}} \cos \left[\mathrm{n}_{\mathrm{w}}(\theta+\gamma)\right]
$$

where $\theta$ is the angular coordinate starting from the negative $O x$ axis and $(x, y)$ are the coordinates of the rotor centre.

\section{Methods for analysing the dynamic behaviour of wave journal bearings}

The analysis of the dynamic behaviour of the journal bearings that support a rotor is of practical importance because under small loads the journal bearings can become unstable. In most of the practical cases, the sleeve is rigid and the rotor rotates freely inside the bearing clearance. When the motion becomes unstable the rotor can touch the sleeve, a phenomenon that can destroy the bearing. There are also other situations when the bearing sleeve is mobile while the shaft is rigid. In this case, when the fluid film becomes unstable, the sleeve can come into contact with the rotor, damaging the bearing. The dynamic behaviour of the wave journal bearing for both types of motions is analysed in the next sections.

\subsection{Analyse of the wave bearing dynamic behaviour when the sleeve is rigid and the rotor rotates freely inside the bearing clearance}

For this type of motion, the bearing sleeve is considered rigid and the rotor rotates freely inside the bearing clearance. Two different approaches can be used to analyze the dynamic stability of the wave journal bearing in this case:

- the identification of the bearing stability threshold based on the critical mass values (Lund, 1987);

- transient approach based on nonlinear theory (Kirk \& Gunter, 1976; Vijayaraghavan \& Brewe, 1992; Ene et al., 2008 b).

The critical mass method is very popular because of its simplicity and limited computational time requirements. The main disadvantage of this method is that no bearing information can 
be obtained after the appearance of the unstable whirl motion. The post-whirl motion can be simulated only with a transient method. The major inconvenience of the transient approach is that it requires large computational time.

\section{Transient analysis}

In absence of any external load, the equations of motion of the rotor centre can be written in a fixed system reference $\mathrm{O}_{\mathrm{s}} \mathrm{xy}$ (Fig. 2) as:

$$
\begin{aligned}
& m \ddot{x}=F_{x}+m \rho \omega^{2} \cos \omega t \\
& m \ddot{y}=F_{y}+m \rho \omega^{2} \sin \omega t
\end{aligned}
$$

where $F_{x}, F_{y}$ are the components of the fluid film force, $\rho$ - the shaft run-out, $2 m$ - the rotor mass, $\omega$ - the rotational velocity, and $(x, y)$ - the coordinates of the shaft centre.

The components of the fluid force $F_{x}$ and $F_{y}$ are obtained by integrating the pressure - $p$ over the entire film:

$$
\left[\begin{array}{l}
\mathrm{F}_{\mathrm{x}} \\
\mathrm{F}_{\mathrm{y}}
\end{array}\right]=\mathrm{R} \int_{0}^{\mathrm{L}} \int_{0}^{2 \pi} \mathrm{p}\left[\begin{array}{c}
\cos \theta \\
\sin \theta
\end{array}\right] \mathrm{d} \theta \mathrm{dz}
$$

where $\mathrm{R}$ is the shaft radius, $\mathrm{L}$ is the bearing length, and $\theta$ and $\mathrm{z}$ are the angular and axial coordinates, respectively. At a particular moment of time, the pressure distribution is described by the transient Reynolds equation:

$$
\frac{1}{\mathrm{R}^{2}} \frac{\partial}{\partial \theta}\left(\frac{\mathrm{h}^{3}}{\mathrm{k}_{\theta}} \frac{\partial \mathrm{p}}{\partial \theta}\right)+\frac{\partial}{\partial \mathrm{z}}\left(\frac{\mathrm{h}^{3}}{\mathrm{k}_{\mathrm{z}}} \frac{\partial \mathrm{p}}{\partial \mathrm{z}}\right)=6 \mu \omega \frac{\partial \mathrm{h}}{\partial \theta}+12 \mu \dot{\mathrm{x}} \cos \theta+12 \mu \dot{y} \sin \theta
$$

where $\mu$ is the oil viscosity, and $k_{\theta}$ and $k_{z}$ are correction coefficients for turbulent flow. The correction coefficients can be calculated by using Constantinescu's model of turbulence (Constantinescu et. al, 1985; Frêne \& Constantinescu, 1975). According to this model, the correction coefficients are function of an effective Reynolds number:

$$
\begin{aligned}
& k_{\theta}=12+0.0136 \operatorname{Re}_{\text {eff }}^{0.9} \\
& k_{z}=12+0.0044 \operatorname{Re}_{\text {eff }}^{0.9}
\end{aligned}
$$

The first signs of turbulence appear when the local mean Reynolds number $\mathrm{Re}_{\mathrm{m}}$ is greater than local critical Reynolds number $\mathrm{Re}_{\mathrm{cr}}$. The flow becomes dominantly turbulent when the mean Reynolds number $\operatorname{Re}_{m}$ is greater than $2 \operatorname{Re}_{\mathrm{cr}}$. With these assumptions, the effective Reynolds number is:

$$
\operatorname{Re}_{\text {eff }}=\left\{\begin{array}{cl}
0 & \operatorname{Re}_{\mathrm{m}}<\operatorname{Re}_{\mathrm{cr}} \\
\left(\frac{\operatorname{Re}_{\mathrm{m}}}{\operatorname{Re}_{\mathrm{cr}}-1}\right) \operatorname{Re}_{1} & \operatorname{Re}_{\mathrm{cr}} £ \operatorname{Re}_{\mathrm{m}} £ 2 \operatorname{Re}_{\mathrm{cr}} \\
\operatorname{Re}_{1} & \operatorname{Re}_{\mathrm{m}}>2 \operatorname{Re}_{\mathrm{cr}}
\end{array}\right.
$$

where: 


$$
\begin{aligned}
& \operatorname{Re}_{\mathrm{cr}}=\min \left(41.2 \sqrt{\frac{\mathrm{R}}{\mathrm{h}}}, 2000\right) \\
& \operatorname{Re}_{1}=\frac{\rho \operatorname{R\omega h}}{\mu} \\
& \operatorname{Re}_{\mathrm{m}}=\frac{2 \rho \mathrm{q}}{\mu}
\end{aligned}
$$

and $\mathrm{q}$ is the total flow.

The numerical and experimental studies show that, due to the pumping effect of the wave profile, the oil flow for the wave bearings is greater than the flow for plain journal bearings. Moreover, the greater the amplitude ratio is, the greater the flow is. Consequently, it can be assumed that the total heat generated in the fluid film is removed exclusively through the fluid transport (convection). The heat removed from the fluid through conduction to the bearing walls can be neglected. Also, the conduction within the fluid itself is neglected. In order to minimize the computation time, a constant mean temperature is assumed to occur over entire film. With these assumptions, the increase of the lubricant temperature (the difference between the temperature of the lubricant entering the film and the constant mean temperature of the film) is given by:

$$
\Delta \mathrm{T}=\frac{\mathrm{F}_{\mathrm{f}} \mathrm{R} \omega}{\rho \mathrm{c}_{\mathrm{v}} \mathrm{q}_{\text {lat }}}
$$

where $c_{v}$ is the lubricant specific heat, $q_{l a t}$ is the rate of lateral flow and $F_{f}$ is the friction force. The bearing trajectory is obtained by integrating the non-linear differential equations of the motion, Eqs. (4). A fourth order Runge-Kutta algorithm is used to integrate the motion equations. At each time step, an initial pressure distribution corresponding to the motion parameters, mean film temperature, and correction coefficients for turbulent flow from the previous moment of time is first obtained by integrating the Reynolds equation, Eq. 6 . The Reynolds equation is solved by using a central difference scheme combined with a Gauss Seidel method. The Reynolds boundary conditions are assumed for the cavitation region.

Next, an energy balance is performed and a new mean film temperature is obtained, Eq. 10 . The lubricant properties (viscosity, density and specific heat) are then updated for the new mean film temperature. A new set of correction coefficients corresponding to the new pressure distribution is then calculated, Eqs. 8-9. The Reynolds equation is integrated again for the new values of the correction coefficients and lubricant viscosity. The iterative process is repeated until the relative errors for the correction coefficients are smaller than prescribed values. Furthermore, the fluid film forces are calculated by integrating the final pressure distribution over the entire film, Eqs. 5. Then the equations of motion, Eqs. 4, are integrated to determine the parameters of the motion for the next time step. The algorithm is repeated until the orbit of the journal centre is completed.

\section{The critical mass approach}

The bearing stability can be also analysed by evaluating the critical mass. The critical mass represents the upper limit for stability. If the rotor mass is smaller than the critical mass, the system is stable and the rotor centre returns to its equilibrium position. Particularly, in absence of any external load, the rotor centre rotates with a small radius around the bearing centre. The size of the radius depends on the shaft run-out. If the rotor mass is greater than 
the critical mass then the rotor centre leaves its static equilibrium position and the system is unstable.

The critical mass is function of the dynamic coefficients of the bearing:

$$
\mathrm{m}_{\mathrm{cr}}=\frac{\mathrm{K}_{\mathrm{s}}}{\mathrm{\gamma}_{\mathrm{s}}^{2}}
$$

where $K_{s}$ is the effective bearing stiffness:

$$
K_{s}=\frac{B_{x x} K_{y y}+B_{y y} K_{x x}-B_{x y} K_{y x}-B_{y x} K_{x y}}{B_{x x}+B_{y y}}
$$

and $\gamma_{\mathrm{s}}$ is the instability whirl frequency:

$$
\gamma_{s}=\sqrt{\frac{\left(K_{x x}-K_{s}\right)\left(K_{y y}-K_{s}\right)-K_{x y} K_{y x}}{B_{x x} B_{y y}-B_{x y} B_{y x}}}
$$

The dynamic coefficients can be obtained by integrating the pressure gradients:

$$
\begin{aligned}
& {\left[\begin{array}{ll}
K_{x x} & K_{x y} \\
K_{y x} & K_{y y}
\end{array}\right]=R \int_{-\frac{L}{2}}^{\frac{L}{2}} \int_{0}^{2 \pi}\left[\begin{array}{ll}
p_{x} \cos \theta & p_{y} \cos \theta \\
p_{x} \sin \theta & p_{y} \sin \theta
\end{array}\right] d \theta d z} \\
& {\left[\begin{array}{ll}
\mathrm{B}_{\mathrm{xx}} & \mathrm{B}_{\mathrm{xy}} \\
\mathrm{B}_{\mathrm{yx}} & \mathrm{B}_{\mathrm{yy}}
\end{array}\right]=\mathrm{R} \int_{-\frac{\mathrm{L}}{2}}^{\frac{\mathrm{L}}{2}} \int_{0}^{2 \pi}\left[\begin{array}{ll}
\mathrm{p}_{\dot{\mathrm{x}}} \cos \theta & \mathrm{p}_{\dot{\mathrm{y}}} \cos \theta \\
\mathrm{p}_{\dot{\mathrm{x}}} \sin \theta & \mathrm{p}_{\dot{\mathrm{y}}} \sin \theta
\end{array}\right] \mathrm{d} \theta \mathrm{dz}}
\end{aligned}
$$

The pressure gradient distributions are obtained by solving the following partial differential equations:

$$
\begin{aligned}
& \frac{1}{\mathrm{R}^{2}} \frac{\partial}{\partial \theta}\left(\frac{\mathrm{h}^{3}}{\mathrm{k}_{\theta} \mu} \frac{\partial \mathrm{p}_{\mathrm{x}}}{\partial \theta}\right)+\frac{\partial}{\partial \mathrm{z}}\left(\frac{\mathrm{h}^{3}}{\mathrm{k}_{\mathrm{z}} \mu} \frac{\partial \mathrm{p}_{\mathrm{x}}}{\partial \mathrm{z}}\right)=-\frac{\omega}{2}\left(\sin \theta+3 \frac{\cos \theta}{\mathrm{h}} \frac{\partial \mathrm{h}}{\partial \theta}\right)-\frac{\mathrm{h}^{3}}{4 \mu \mathrm{R}^{2}} \frac{\partial \mathrm{p}_{0}}{\partial \theta} \frac{\partial}{\partial \theta}\left(\frac{\cos \theta}{\mathrm{h}}\right) \\
& \frac{1}{\mathrm{R}^{2}} \frac{\partial}{\partial \theta}\left(\frac{\mathrm{h}^{3}}{\mathrm{k}_{\theta} \mu} \frac{\partial \mathrm{p}_{\mathrm{y}}}{\partial \theta}\right)+\frac{\partial}{\partial \mathrm{z}}\left(\frac{\mathrm{h}^{3}}{\mathrm{k}_{\mathrm{z}} \mu} \frac{\partial \mathrm{p}_{\mathrm{y}}}{\partial \mathrm{z}}\right)=\frac{\omega}{2}\left(\cos \theta-3 \frac{\sin \theta}{\mathrm{h}} \frac{\partial \mathrm{h}}{\partial \theta}\right)-\frac{\mathrm{h}^{3}}{4 \mu \mathrm{R}^{2}} \frac{\partial \mathrm{p}_{0}}{\partial \theta} \frac{\partial}{\partial \theta}\left(\frac{\sin \theta}{\mathrm{h}}\right) \\
& \frac{1}{\mathrm{R}^{2}} \frac{\partial}{\partial \theta}\left(\frac{\mathrm{h}^{3}}{\mathrm{k}_{\theta} \mu} \frac{\partial \mathrm{p}_{\dot{\mathrm{x}}}}{\partial \theta}\right)+\frac{\partial}{\partial \mathrm{z}}\left(\frac{\mathrm{h}^{3}}{\mathrm{k}_{\mathrm{z}} \mu} \frac{\partial \mathrm{p}_{\dot{\mathrm{x}}}}{\partial \mathrm{z}}\right)=\cos \theta \\
& \frac{1}{\mathrm{R}^{2}} \frac{\partial}{\partial \theta}\left(\frac{\mathrm{h}^{3}}{\mathrm{k}_{\theta} \mu} \frac{\partial \mathrm{p}_{\dot{\mathrm{y}}}}{\partial \theta}\right)+\frac{\partial}{\partial \mathrm{z}}\left(\frac{\mathrm{h}^{3}}{\mathrm{k}_{\mathrm{z}} \mu} \frac{\partial \mathrm{p}_{\dot{\mathrm{y}}}}{\partial \mathrm{z}}\right)=\sin \theta
\end{aligned}
$$

where the steady-state pressure $\mathrm{p}_{0}$ is given by the steady-state Reynolds equation:

$$
\frac{1}{\mathrm{R}^{2}} \frac{\partial}{\partial \theta}\left(\frac{\mathrm{h}^{3}}{\mathrm{k}_{\theta} \mu} \frac{\partial \mathrm{p}_{0}}{\partial \theta}\right)+\frac{\partial}{\partial \mathrm{z}}\left(\frac{\mathrm{h}^{3}}{\mathrm{k}_{\mathrm{z}} \mu} \frac{\partial \mathrm{p}_{0}}{\partial \mathrm{z}}\right)=\frac{\omega}{2} \frac{\partial \mathrm{h}}{\partial \theta}
$$


The first problem that must be solved when using the critical mass approach is to determine the equilibrium position of the rotor centre. At the equilibrium, in absence of any external force, the static component of the fluid film force must be vertical and equal to the rotor weight. The equilibrium position is determined by integrating the steady-state Reynolds equation, Eq. 16, for different positions of the rotor centre until the resultant reaction load is vertical and equal to the external load. An iterative algorithm based on the bisection method was developed for this purpose. For each position of the shaft, the turbulence correction coefficients are determined by successive iterations using an algorithm similar to that used for the transient approach. The steady-state Reynolds equation, Eq. 16, is discretized with a finite difference scheme. The resultant system of equations is solved with a successive overrelaxation method. The Reynolds boundary conditions are assumed in the cavitation regions. The two ends of the bearing are considered at atmospheric pressure. In the oil supply pockets, the pressure is assumed to be equal to the supply pressure.

Having the equilibrium position of the shaft and the turbulence correction coefficients corresponding to this position, the pressure gradients can now be determined by integrating Eqs. 15 with a finite difference scheme. The pressure gradients are assumed to be zero at the two ends of the bearing, in the pocket regions and in the cavitation regions. The dynamic coefficients are evaluated by integrating the pressure gradients distribution along the fluid film, Eqs. 14, and the critical mass is then determined with Eqs. 11-13.

\section{Numerical simulations}

The two methods are used to predict the dynamic behaviour of a three-wave bearing having a length of $27.5 \mathrm{~mm}$, a radius of the mean circle of waves of $15 \mathrm{~mm}$, and a clearance of 35 microns. The rotor mass corresponding to one bearing is $0.825 \mathrm{~kg}$. A 2 micron rotor run-out is considered for the numerical simulations. Synthetic turbine oil Mil-L-23699 is used as a lubricant. The bearing has also three supply pockets situated at $120^{\circ}$ one from each other. The theoretical methods are validated by comparing the numerical results obtained with the two methods one to each other and also to experimental data (Dimofte et al., 2004).

The numerical simulations and the experiments show that for wave amplitudes greater than 0.3 , the fluid film of the analyzed wave bearing is stable even at speeds of $60000 \mathrm{rpm}$, supply pressures of $0.152 \mathrm{MPa}$, and oil inlet temperatures of $190^{\circ} \mathrm{C}$. For example the rotor centre trajectory predicted with the transient method for a wave amplitude ratio of 0.305 and a speed of $60000 \mathrm{rpm}$ is presented in Fig. 3. The rotor centre rotates on a closed orbit with a radius almost equal to the run-out. The FFT analysis of the motion is presented in Fig. 4. For comparison, the FFT analysis of the experimental signal is shown in Fig. 5. It can be seen that both FFT diagrams contains only the synchronous frequency. The presence of only the synchronous frequency indicates a stable fluid film. The same conclusion can be drawn from the critical mass approach. The variation of the critical mass with the speed is shown in Fig. 6 . Because the critical mass is greater than the rotor mass, it can be concluded that the fluid film is stable for speeds up to $60000 \mathrm{rpm}$.

For wave amplitudes smaller than 0.3 , a stability threshold can be found. The experiments and the numerical simulations show that the threshold of stability depends on the wave amplitude, oil supply pressure and inlet temperature. For instance, for a wave amplitude of 0.075 , a supply pressure of $0.276 \mathrm{MPa}$, and an oil temperature inlet of $126^{\circ} \mathrm{C}$, the threshold of stability is around $39000 \mathrm{rpm}$. The variation of the critical mass with the rotational speed is presented in Fig. 7. The diagram shows that the critical mass is greater than the mass of the shaft related to one bearing for speeds smaller than $39000 \mathrm{rpm}$. The critical mass is very 
close to the rotor mass around $39000 \mathrm{rpm}$ and then it becomes smaller than the rotor mass. Consequently, it may be concluded that the fluid film of the wave bearing is unstable for rotational speeds greater than $39000 \mathrm{rpm}$.

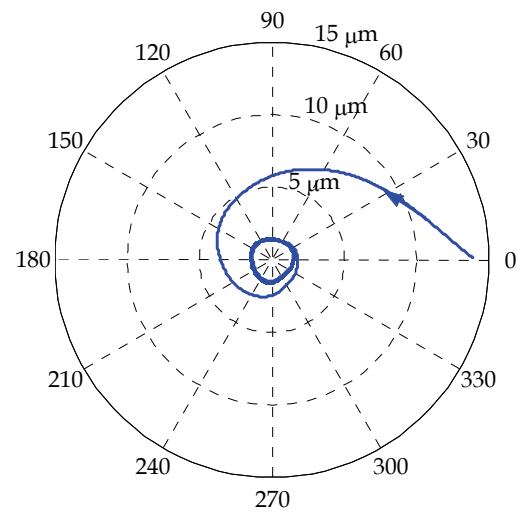

Fig. 3. Trajectory of the rotor centre for a wave amplitude of 0.305 , a rotational speed of $60000 \mathrm{rpm}$, and a supply pressure of $0.152 \mathrm{MPa}$

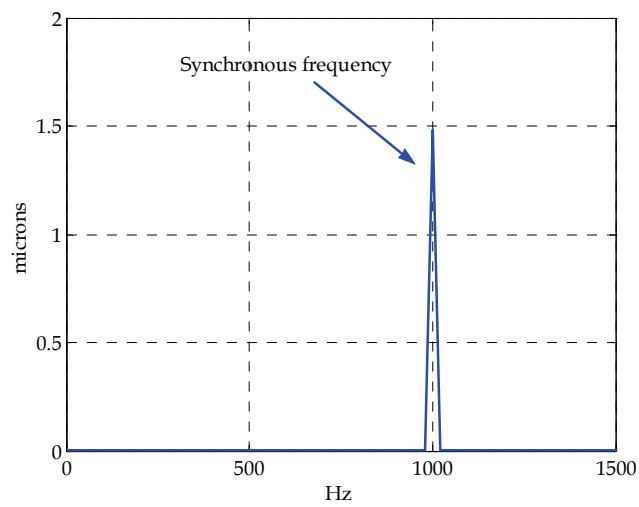

Fig. 4. FFT diagram of the motion for a wave amplitude of 0.305 , a rotational speed of 60000 rpm, and a supply pressure of $0.152 \mathrm{MPa}$

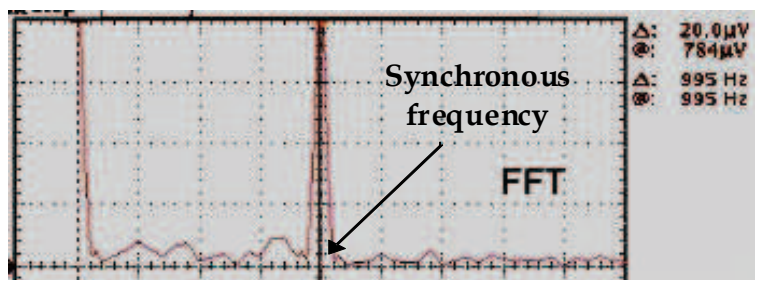

Fig. 5. FFT diagram of the experimental signal for a wave amplitude of 0.305 , a rotational speed of $60000 \mathrm{rpm}$, and a supply pressure of $0.152 \mathrm{MPa}$ 


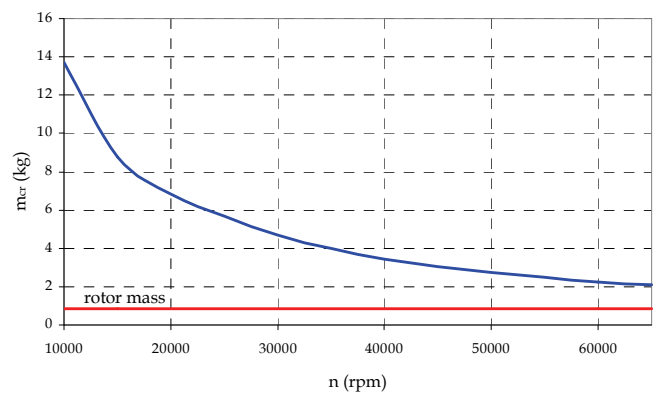

Fig. 6. Critical mass as function of the rotational speed for a wave amplitude of 0.305 and a supply pressure of $0.152 \mathrm{MPa}$

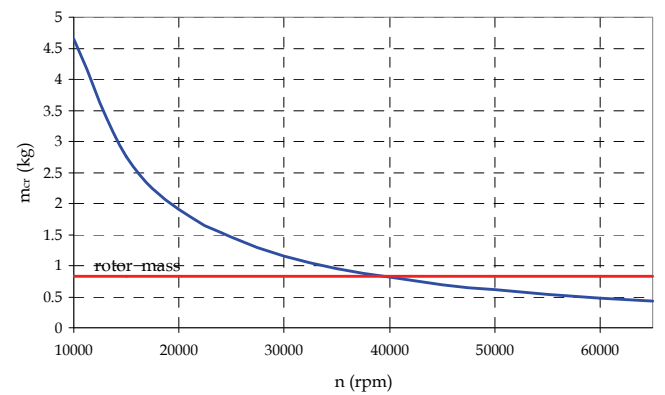

Fig. 7. Critical mass as function of running speed for a wave amplitude of 0.075 and a supply pressure of $0.276 \mathrm{MPa}$

The trajectories of the journal centre are very different for stable and unstable conditions. For example, the trajectory of the journal centre for a rotational speed of $36000 \mathrm{rpm}$, which corresponds to a stable condition, is presented in Fig. 8. In this case, the journal centre rotates with one frequency around the sleeve centre on a closed orbit having the radius almost equal to the rotor run-out. The FFT analyses of the numerically simulated motion (Fig. 9) and of the motion recorded from experiments (Fig. 10) reveal that the motion frequency is equal to the synchronous frequency.

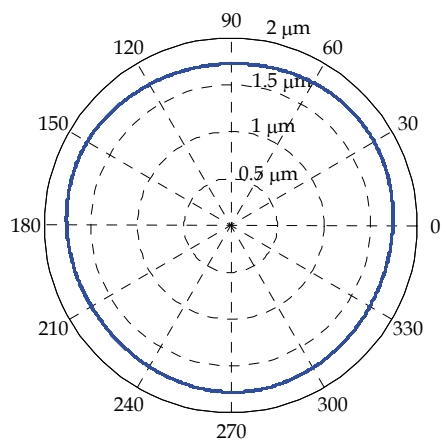

Fig. 8. Trajectory of the rotor centre for a wave amplitude of 0.075 , a rotational speed of $36000 \mathrm{rpm}$ and a supply pressure of $0.276 \mathrm{MPa}$ 


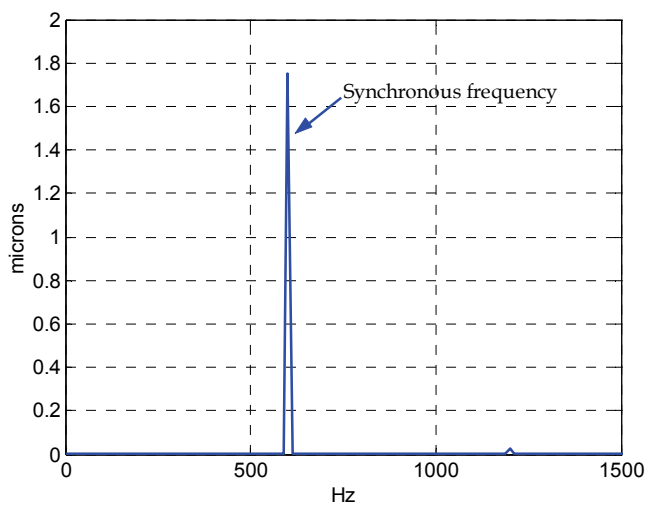

Fig. 9. FFT diagram of the motion for a wave amplitude of 0.075 , a rotational speed of 36000 rpm and a supply pressure of $0.276 \mathrm{MPa}$

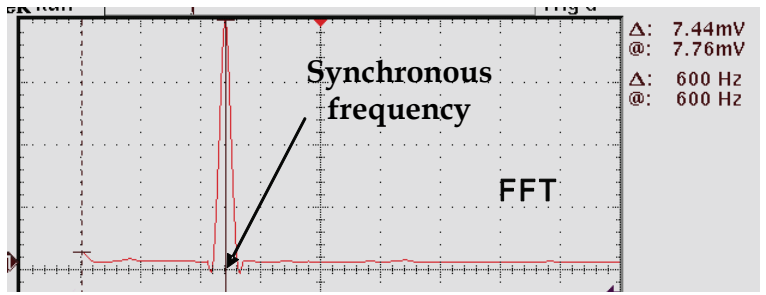

Fig. 10. FFT diagram of the experimental signal for a wave amplitude of 0.075 , a rotational speed of $36000 \mathrm{rpm}$ and a supply pressure of $0.276 \mathrm{MPa}$

If the rotational speed is increased to the stability threshold (39000 rpm), an incipient subsynchronous frequency can be detected (Figs. 11 and 12). The journal centre rotates in this case on a limit cycle with two frequencies - the synchronous and the sub-synchronous frequency (Fig. 13).

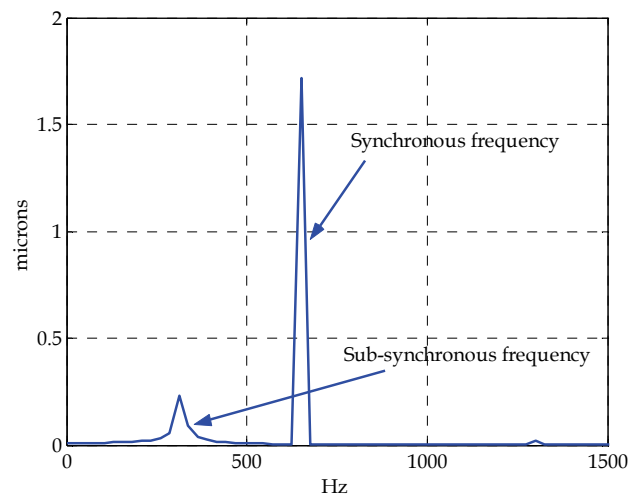

Fig. 11. FFT diagram of the motion for a wave amplitude of 0.075 , a rotational speed of 39000 rpm and a supply pressure of $0.276 \mathrm{MPa}$ 


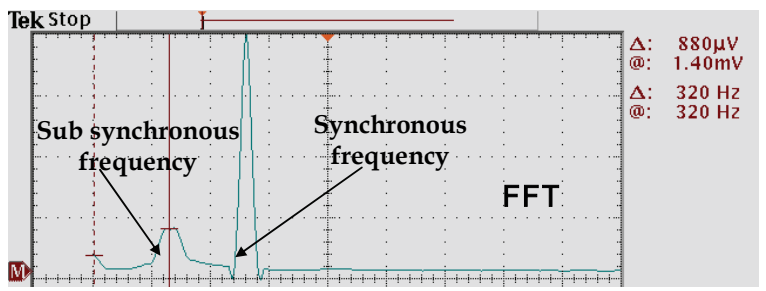

Fig. 12. FFT diagram of the experimental signal for a wave amplitude of 0.075 , a rotational speed of $39000 \mathrm{rpm}$ and a supply pressure of $0.276 \mathrm{MPa}$

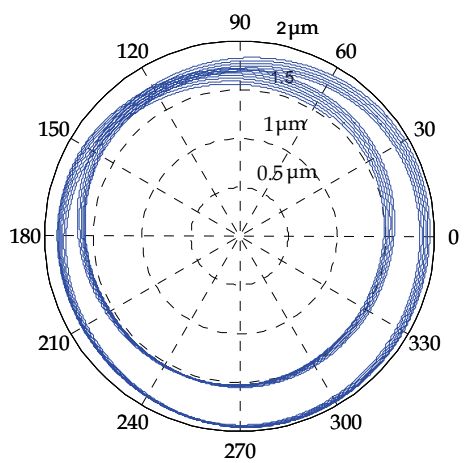

Fig. 13. Trajectory of the rotor centre for a wave amplitude of 0.075 , a rotational speed of $39000 \mathrm{rpm}$ and a supply pressure of $0.276 \mathrm{MPa}$

For speeds greater than $39000 \mathrm{rpm}$, the sub-synchronous frequency becomes dominant. As an exemplification, the FFT diagrams of the numerically simulated motion and of the experimental signal for a rotating speed of $44000 \mathrm{rpm}$ are shown in Figs. 14 and 15. The trajectory of the rotor centre is presented in Fig. 16. The journal centre rotates on a limit cycle with a radius greater than the rotor run-out. However, due to the particular geometry of the wave bearing, the rotor centre maintains its trajectory inside the bearing clearance.

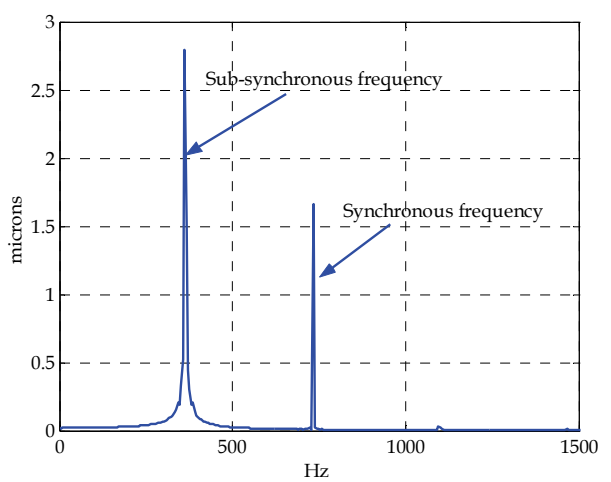

Fig. 14. FFT diagram of the motion for a wave amplitude of 0.075 , a rotational speed of 44000 rpm and a supply pressure of $0.276 \mathrm{MPa}$ 


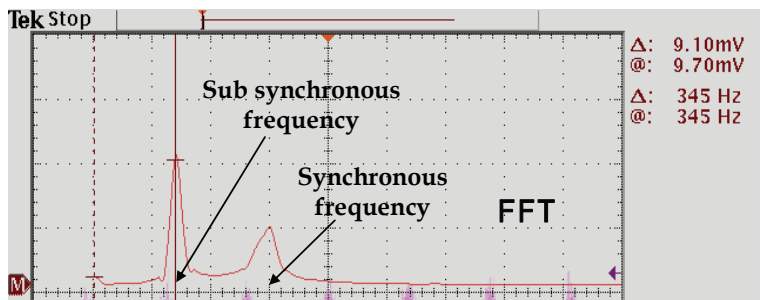

Fig. 15. FFT analysis of the experimental signal for a wave amplitude of 0.075 , a rotational speed of $44000 \mathrm{rpm}$ and a supply pressure of $0.276 \mathrm{MPa}$

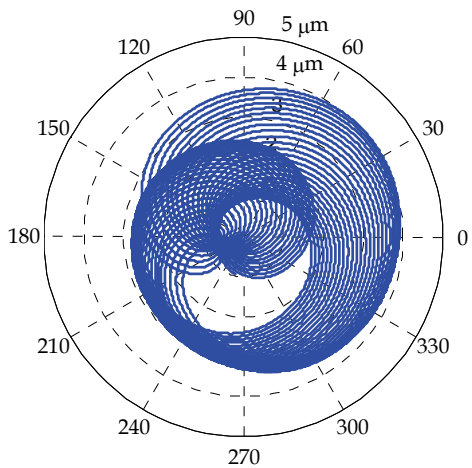

Fig. 16. Trajectory of the rotor centre for a wave amplitude of 0.075 , a rotational speed of $44000 \mathrm{rpm}$ and a supply pressure of $0.276 \mathrm{MPa}$

An increase of the supply pressure to $0.414 \mathrm{MPa}$ makes the fluid film stable for speeds up to $60000 \mathrm{rpm}$. The critical mass becomes greater than the rotor mass (Fig. 17), the subsynchronous frequency disappears and the rotor centre rotates with the synchronous frequency on a closed orbit with the radius almost equal to the rotor run-out. As an illustration, the FFT diagrams of the experimental signal, theoretical motion and the trajectory of the rotor centre for a rotating speed of $60000 \mathrm{rpm}$ are shown in Figs. 18, 19 and 20 , respectively.

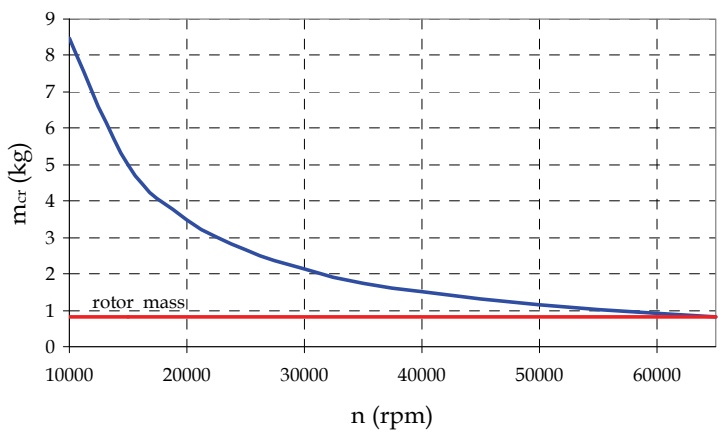

Fig. 17. Critical mass as function of running speed for a wave amplitude of 0.075 and a supply pressure of $0.414 \mathrm{MPa}$ 
It can be noticed from the above simulations that both the wave amplitude and the oil supply pressure strongly influence the bearing stability. The bearing stability also depends on the oil inlet temperature (Lambrulescu et al., 2003).

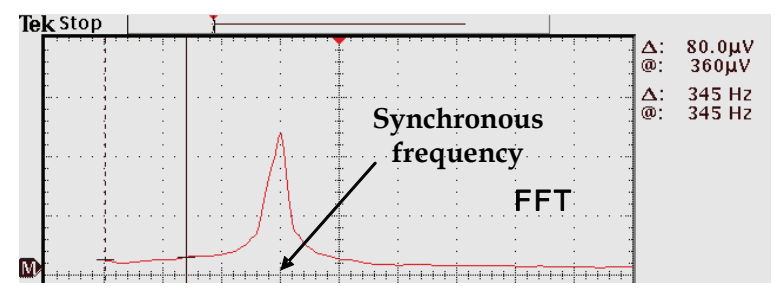

Fig. 18. FFT analysis of the experimental signal for a wave amplitude of 0.075 , a rotational speed of $60000 \mathrm{rpm}$ and a supply pressure of $0.414 \mathrm{MPa}$

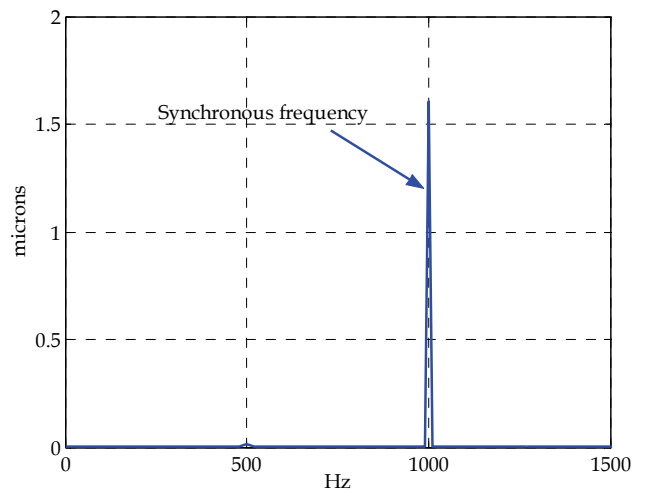

Fig. 19. FFT a diagram of the motion for a wave amplitude of 0.075 , a rotational speed of $60000 \mathrm{rpm}$ and a supply pressure of $0.414 \mathrm{MPa}$

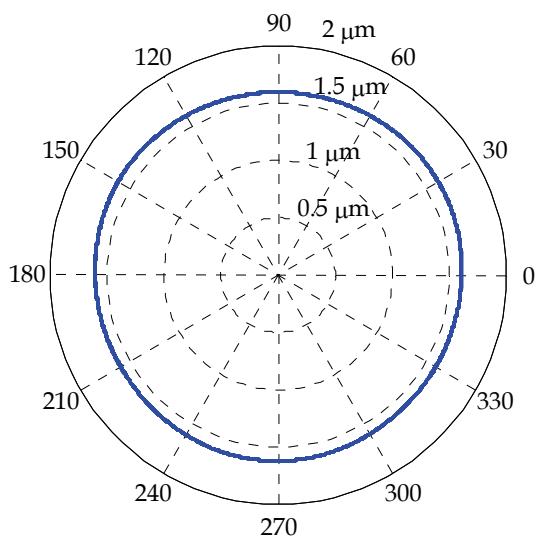

Fig. 20. Trajectory of the rotor centre for a wave amplitude of 0.075 , a rotational speed of $60000 \mathrm{rpm}$ and a supply pressure of $0.414 \mathrm{MPa}$ 


\subsection{Analyse of the wave bearing dynamic behaviour when the bearing sleeve is mobile}

For this type of motion, the bearing sleeve is mobile and the rotor rotates around a fixed axis with an angular velocity $\omega$. The rotor has an inherent unbalance characterized by a small run-out $\rho$. The bearing sleeve is connected with the machine housing by an elastic element (Fig. 21) having the stiffness and damping coefficients in $x$ and $y$ directions $k_{x}, k_{y}$ and $b_{x}, b_{y}$, respectively. The geometry of the motion can be seen in Fig. 22. Two systems of reference are used to study the motion: a fixed system $O x^{\prime} y^{\prime}$ with the origin $\mathrm{O}$ situated on the fixed axis around which the rotor rotates, and a mobile system of reference $\mathrm{O}_{\mathrm{s}} \mathrm{xy}$ with the origin $\mathrm{O}_{\mathrm{s}}$ in the sleeve centre (Fig. 22).
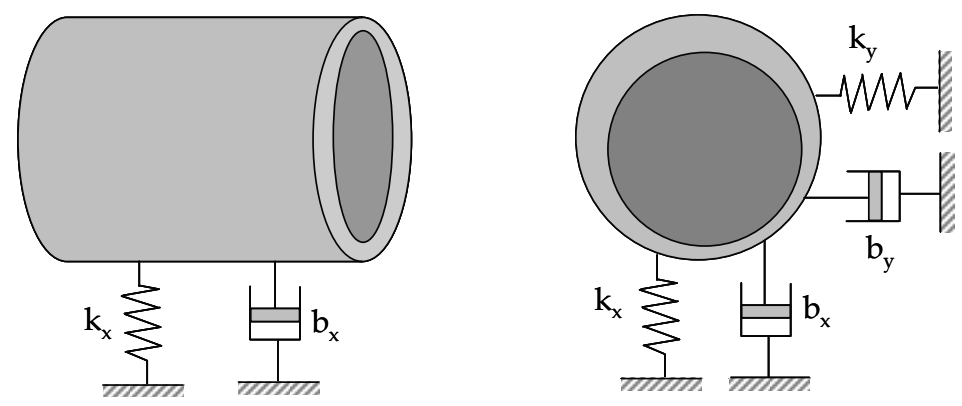

Fig. 21. Wave bearing with the sleeve supported by an elastic element

Because of its run-out $\rho$, the trajectory of the rotor centre in the $O x^{\prime} y^{\prime}$ system of reference is a circle with radius $\rho$. Therefore the coordinates of the rotor centre in the $\mathrm{Ox}^{\prime} \mathrm{y}^{\prime}$ system are:

$$
\begin{aligned}
& \mathrm{x}_{\mathrm{R}}=\mathrm{x}_{\mathrm{R} 0}+\rho \cos \omega \mathrm{t} \\
& \mathrm{y}_{\mathrm{R}}=\mathrm{y}_{\mathrm{R} 0}+\rho \cos \omega \mathrm{t}
\end{aligned}
$$

where $\mathrm{x}_{\mathrm{R} 0}$ and $\mathrm{y}_{\mathrm{R} 0}$ are the coordinates of the rotor centre at the initial moment of time.

In the fixed system of reference $\mathrm{Ox}^{\prime} \mathrm{y}^{\prime}$, the equations of motion for the sleeve centre are:

$$
\begin{aligned}
& m^{\prime} \ddot{x}_{s}=-F_{x}-k_{x} x_{s}-b_{x} \dot{x}_{s} \\
& m^{\prime} \ddot{y}_{s}=-F_{y}-k_{y} y_{s}-b_{y} \dot{y}_{s}
\end{aligned}
$$

where $\mathrm{Fx}, \mathrm{F}_{\mathrm{y}}$ are the components of the fluid film force, $\mathrm{x}_{\mathrm{s}}, \mathrm{y}_{\mathrm{s}}-$ the coordinates of the sleeve centre, and $\mathrm{m}^{\prime}$ - the mass of the sleeve. The fluid film forces are calculated by integrating the pressure distribution over the entire fluid film. The pressure distribution can be obtained by solving the Reynolds equation which in the mobile system of reference $\mathrm{O}_{\mathrm{s}} \mathrm{xy}$ has the following form:

$$
\frac{1}{\mathrm{R}^{2}} \frac{\partial}{\partial \theta}\left(\frac{\mathrm{h}^{3}}{\mathrm{k}_{\theta}} \frac{\partial \mathrm{p}}{\partial \theta}\right)+\frac{\partial}{\partial \mathrm{z}}\left(\frac{\mathrm{h}^{3}}{\mathrm{k}_{\mathrm{z}}} \frac{\partial \mathrm{p}}{\partial \mathrm{z}}\right)=6 \mu \omega \frac{\partial \mathrm{h}}{\partial \theta}+12 \mu\left(\dot{\mathrm{x}}_{\mathrm{r}}-\dot{\mathrm{x}}_{\mathrm{s}}\right) \cos \theta+12 \mu\left(\dot{\mathrm{y}}_{\mathrm{r}}-\dot{\mathrm{y}}_{\mathrm{s}}\right) \sin \theta
$$

where the fluid film thickness is given by:

$$
\mathrm{h}=\mathrm{c}+\left(\mathrm{x}_{\mathrm{r}}-\mathrm{x}_{\mathrm{s}}\right) \cos \theta+\left(\mathrm{y}_{\mathrm{r}}-\mathrm{y}_{\mathrm{s}}\right) \sin \theta+\mathrm{e}_{\mathrm{w}} \cos \left[\mathrm{n}_{\mathrm{w}}(\theta+\gamma)\right]
$$




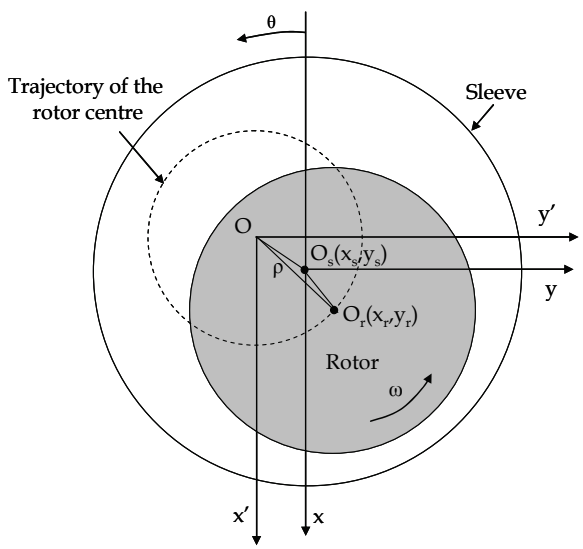

Fig. 22. The geometry of the motion when the bearing sleeve is free to rotate

A numerical algorithm similar to that presented for the previous type of motion was developed to obtain the absolute motion of the sleeve centre and the motion of the sleeve centre relative to the rotor centre. Because the relative motion between the sleeve and the rotor is of practical importance, the numerical simulations will be focused only on this motion.

\section{Numerical simulations}

The above model is used to study the influence of the wave amplitude on the dynamic behaviour of the sleeve of a three - wave bearing having the same geometrical characteristics as the bearing analysed in the previous section (length $-27.5 \mathrm{~mm}$, radius of the mean circle of the waves $-15 \mathrm{~mm}$, clearance - 35 microns, rotor run-out -2 microns). The mass of the sleeve is $0.5 \mathrm{~kg}$. One of the axial ends of the bearing is exposed at a pressure of $0.14 \mathrm{MPa}$. At the other axial end the pressure is $0.5 \mathrm{MPa}$. The stiffness and damping coefficients of the sleeve elastic support are $10000 \mathrm{~N} / \mathrm{m}$ and $10 \mathrm{Ns} / \mathrm{m}$, respectively. To have a better understanding of the influence of the wave profile on the dynamic behaviour of the wave bearing sleeve, a plain

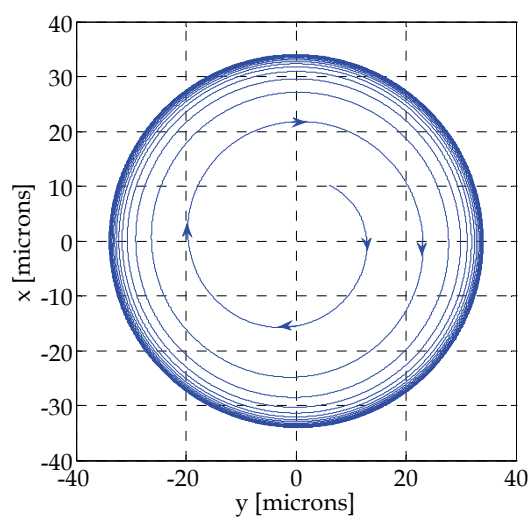

Fig. 23. The trajectory of the sleeve centre of a plain journal bearing with respect to the rotor centre 
journal bearing having the same characteristics as the analysed wave bearing was initially considered. The motion of the sleeve centre of the plain journal bearing with respect to the rotor centre for a rotational speed of $60000 \mathrm{rpm}$ is presented in Fig. 23. The sleeve centre rotates around the rotor centre on a large orbit with a radius very close to the bearing clearance. Therefore the sleeve can come into contact with the rotor and the bearing can be destroyed. The FFT analysis of the motion (Fig. 24) indicates the presence of both the halfwhirl frequency and the synchronous frequency, the half-whirl frequency being dominant.

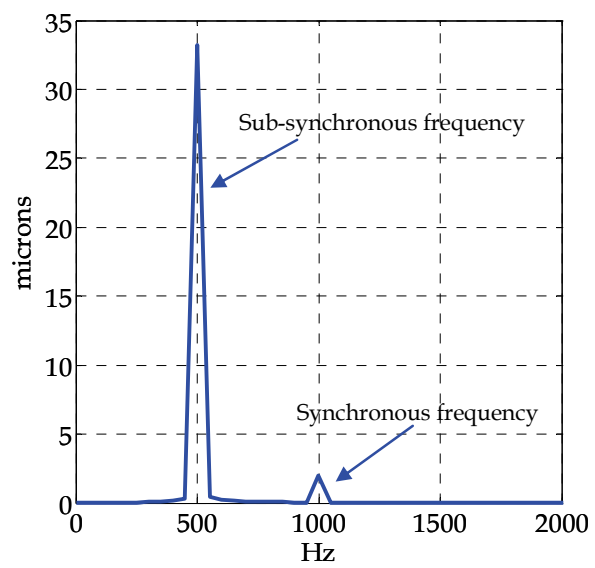

Fig. 24. The FFT diagram of the motion of the plain journal bearing sleeve

For a wave bearing with a wave amplitude ratio of 0.1 , the half-whirl frequency is also dominant (Fig. 25) at $60000 \mathrm{rpm}$. However, the radius of the sleeve centre orbit is much smaller than the bearing clearance (Fig. 26) and the bearing can run safely. It must be also remarked that the trajectory of the sleeve centre with respect to the rotor centre has a shape very similar to shape of the wave bearing profile.

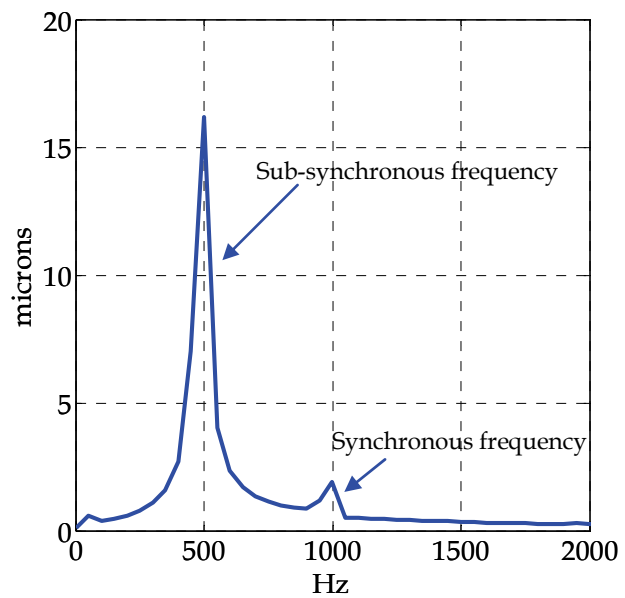

Fig. 25. The FFT diagram of the sleeve centre motion for a wave amplitude ratio of 0.1 


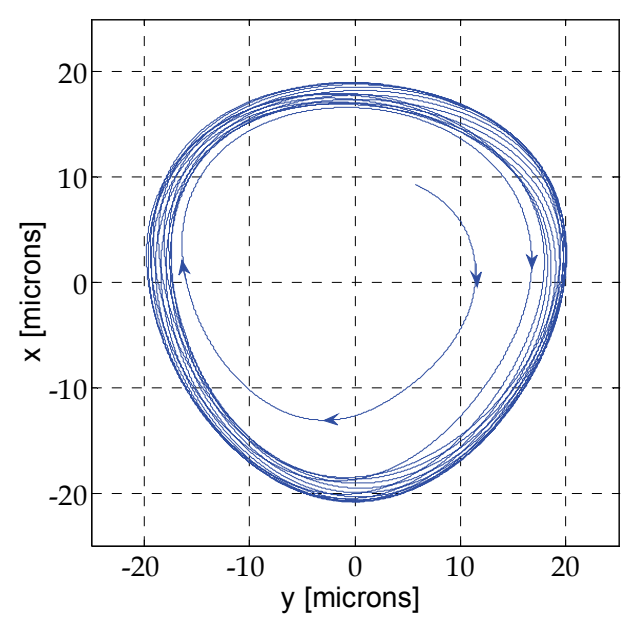

Fig. 26. The trajectory of the sleeve centre with respect to the rotor centre for a wave amplitude ratio of 0.1

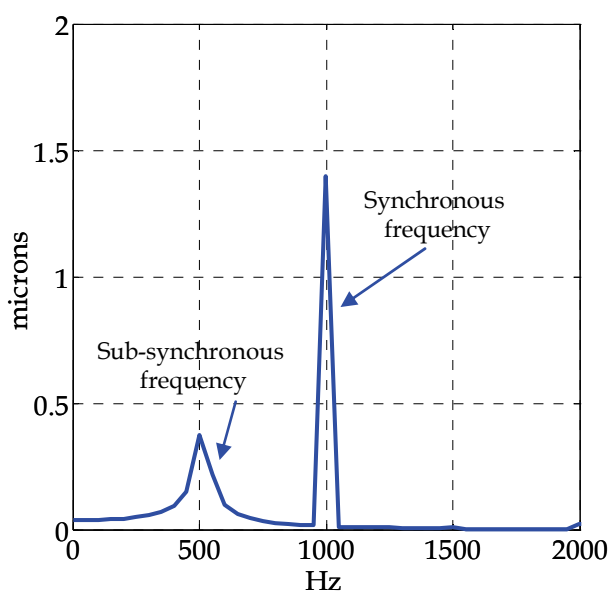

Fig. 27. The FFT diagram of the sleeve centre motion for a wave amplitude ratio of 0.2

For a wave amplitude ratio of 0.2 , the motion still contains both the sub-synchronous and synchronous frequencies. In this case, the synchronous frequency is the main frequency (Fig. 27). The sleeve centre approaches the rotor centre and rotates around it with two frequencies on a small orbit (Fig. 28).

The sub-synchronous frequency completely disappears when the wave amplitude ratio is increased to 0.3 (Fig. 29). The sleeve centre rotates around the rotor centre on a closed orbit with a radius closed to the rotor run-out (Fig. 30).

Therefore it can be concluded that the waves have a stabilising effect on the bearing. Even when the fluid film of the wave bearing is unstable, the sleeve centre maintains its trajectory inside the bearing clearance. 


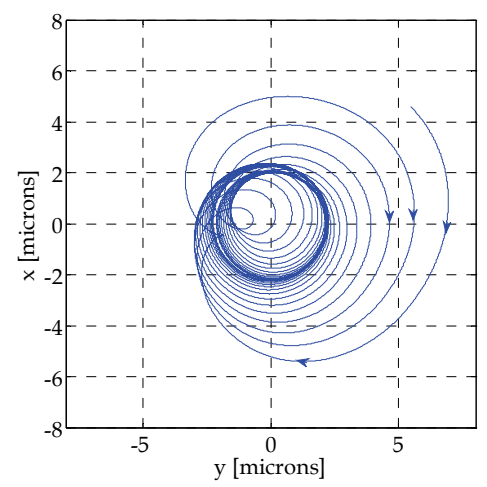

Fig. 28. The trajectory of the sleeve centre with respect to the rotor centre for a wave amplitude ratio of 0.2

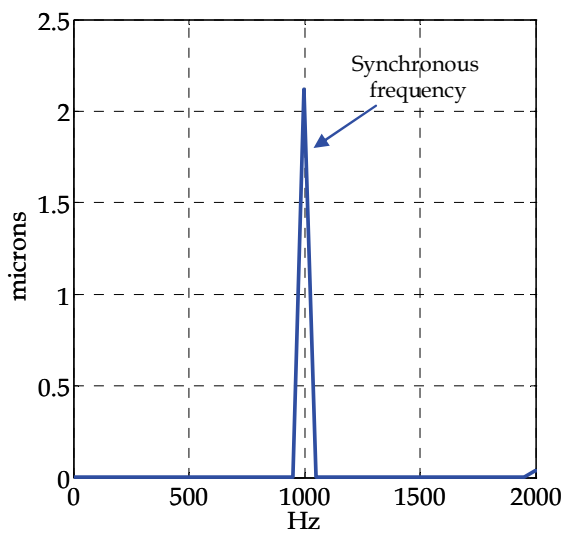

Fig. 29. The FFT diagram of the sleeve centre motion for a wave amplitude ratio of 0.3

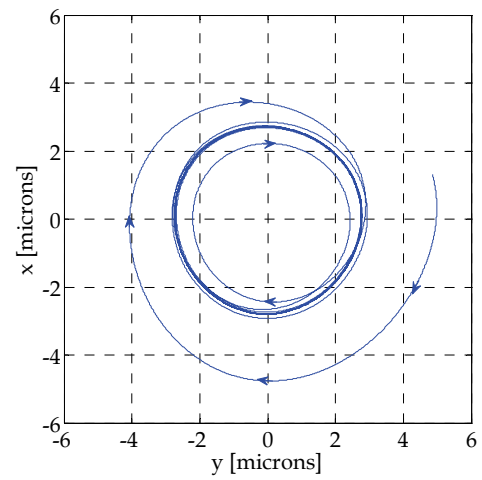

Fig. 30. The trajectory of the sleeve centre with respect to the rotor centre for a wave amplitude ratio of 0.3 


\section{The thrust wave bearing concept}

A typical thrust fluid film bearing used to support an axial load is shown in Fig. 31. As can be seen in Fig. 31, a thrust fluid film bearing consists of a rotating disk (runner) fixed on the shaft and a stationary thrust plate which faces the rotating disk. The gap between the two disks is filled with lubricant. If the active surfaces of both of the disks are flat, no hydrodynamic pressure will be generated in the fluid film and the bearing will not be able to support an axial load. Rayleigh steps or spiral grooves engraved on the active surface of one of the disks can be used, for example, to create hydrodynamic pressure.

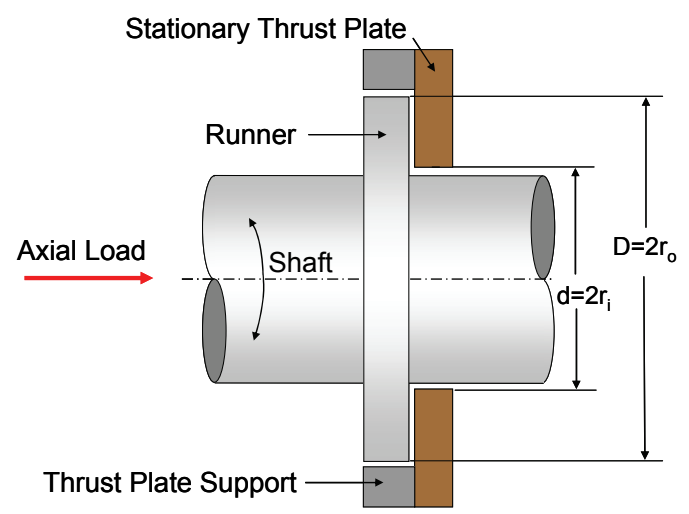

Fig. 31. Typical thrust fluid film bearing

An alternative novel solution is to make a wave profile on the active surface of the stationary disk. As an example, a four-wave thrust plate is shown in Fig. 32. The most important characteristics of a thrust wave bearing are also presented in Fig. 32. The bearing inner radius is $r_{i}$ and the outer radius is $r_{o}$. The wave amplitude $e_{w}$ is measured from the middle plane of the waves. The lubricant is supplied to the bearing through holes and closed pockets. The pockets are orientated in radial direction.

If the thrust bearing is used for positioning the shaft in the axial direction then two thrust plates located on both sides of the runner disk can be used. In this case, the thrust bearing can be lubricated with the oil that comes out from the nearby journal bearing, and the supply system can be eliminated.

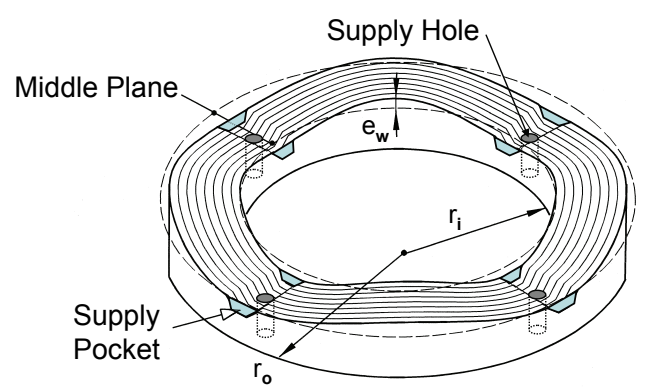

Fig. 32. Wave bearing thrust plate 
The hydrodynamic pressure generated in the fluid film can be obtained by solving the Reynolds equation in cylindrical coordinates:

$$
\frac{\partial}{\partial \theta}\left(h^{3} \frac{\partial p}{\partial \theta}\right)+r \frac{\partial}{\partial r}\left(h^{3} r \frac{\partial p}{\partial r}\right)=6 \mu \omega r^{2} \frac{\partial h}{\partial \theta}
$$

where $\mathrm{p}$ is the pressure, $\mathrm{h}$ - the film thickness, $\mu$ - the oil viscosity, $\omega$ - the angular velocity, $\theta$ - the angular coordinate, and $r$ - the radial coordinate (see Fig. 33).

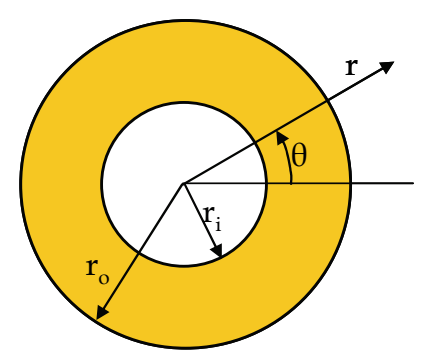

Fig. 33. System of coordinates for the wave thrust bearing

The load $\mathrm{W}$ can be then obtained by numerically integrating the pressure over the entire bearing area:

$$
W=\int_{0}^{2 \pi} \int_{r_{i}}^{r_{0}}(r p) d r d \theta
$$

The increase of the oil temperature when the oil passes through the bearing can be calculated with a method similar to that used for journal bearing.

The influence of the parameters of the wave thrust bearing on its steady-state performance is analysed below. A thrust wave bearing having an inner diameter of $50 \mathrm{~mm}$, an outer diameter of $100 \mathrm{~mm}$, and a wave amplitude of 50 microns was considered. The bearing is supplied with synthetic turbine oil MIL-L-23699 at $65^{\circ}$ C. It is well known that at high temperatures, the "oil viscosity collapse phenomenon" can occur. The direct consequence of the oil viscosity collapse is the dramatic lost of the bearing load capacity. For this reason, a maximum limit of $30^{\circ} \mathrm{C}$ is imposed for the oil temperature increase inside the fluid film. The numerical simulations show that in order to avoid oil temperature increases greater than $30^{\circ} \mathrm{C}$, the analysed thrust wave bearing must have the minimum film thickness greater than 50 microns.

The influence of the number of the waves on the average pressure (the ratio between the load and the bearing surface) and oil temperature increase is first analysed. For example, the evolutions of the average pressure and of the oil temperature increase with the rotational speed for a supply pressure of $0.5 \mathrm{MPa}$, a minimum film thickness of 50 microns and different number of waves are presented in Figs. 34 and 35, respectively.

It can be seen from Fig. 34 that the average pressure has a linear variation with the rotational speed. In addition, the number of the waves has only a small influence on the average pressure (Fig. 34). Nevertheless, the number of the waves can significantly influence the temperature of the oil passing through the bearing. When the number of the waves increases, the number of oil supply holes and pockets increases. An increased number of 


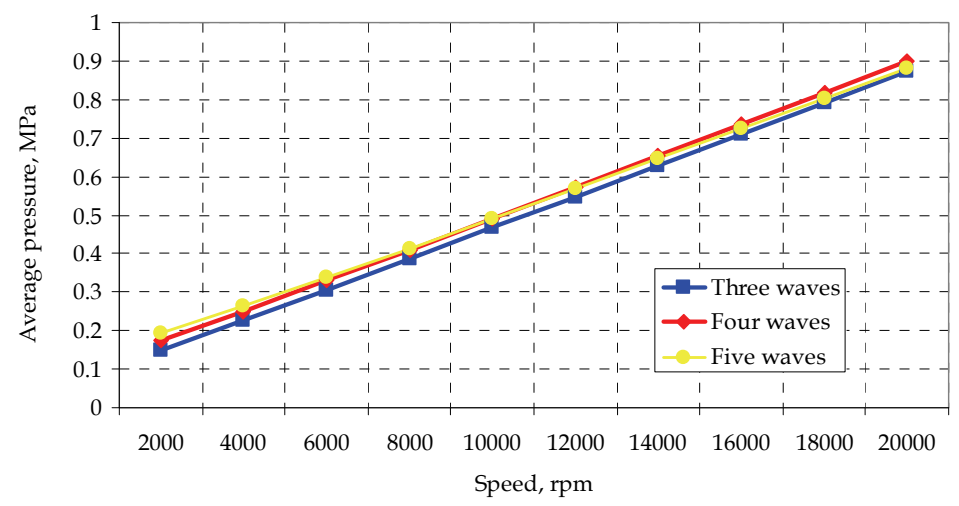

Fig. 34. Average pressure vs. speed for different number of waves (oil supply pressure $0.5 \mathrm{MPa}$, minimum film thickness - 50 microns )

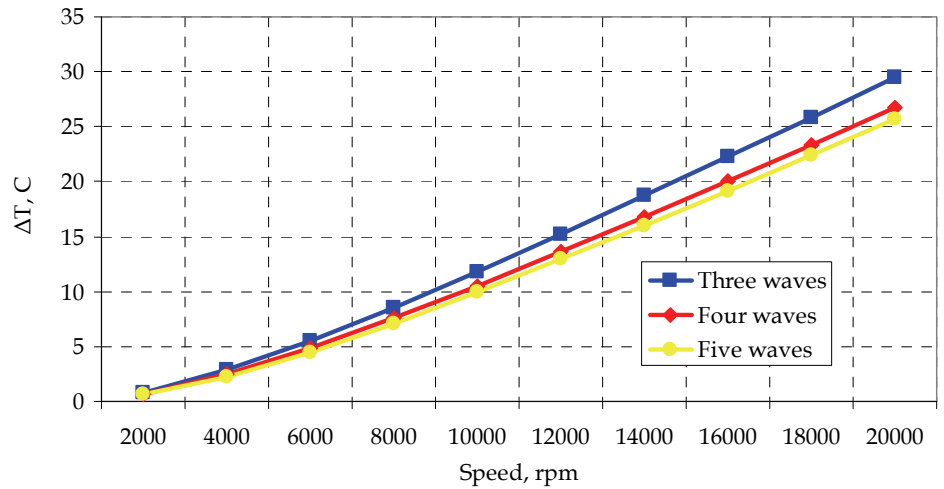

Fig. 35. The increase of the lubricant temperature vs. speed (oil supply pressure $-0.5 \mathrm{MPa}$, minimum film thickness - 50 microns)

supply holes and pockets allows for a better cooling of the bearing. Consequently, the oil temperature increase is smaller for a greater number of waves (Fig. 35). However a significant change of the temperature with the number of the waves can be observed only when the number of waves is increased from three to four.

Next, the influence of the oil supply pressure on the bearing performance was analysed. For example, the evolutions with the rotational speed of the average pressure and oil temperature increase for different supply pressures, a minimum film thickness of 50 microns and a number of five waves are presented in Figs. 36 and 37, respectively.

Fig. 36 shows that the oil supply pressure has only a small influence on the bearing average pressure. The influence of the oil supply pressure on the increase of the oil temperature inside the fluid film can be significant (Fig. 37). From Fig. 37, it can be seen that the oil temperature increase is smaller for higher supply pressures.

Therefore from the numerical simulations it can be concluded that the increase of the oil temperature inside the fluid film can be reduced by increasing the number of the waves or the oil supply pressure. A more significant reduction of the increase of oil temperature 


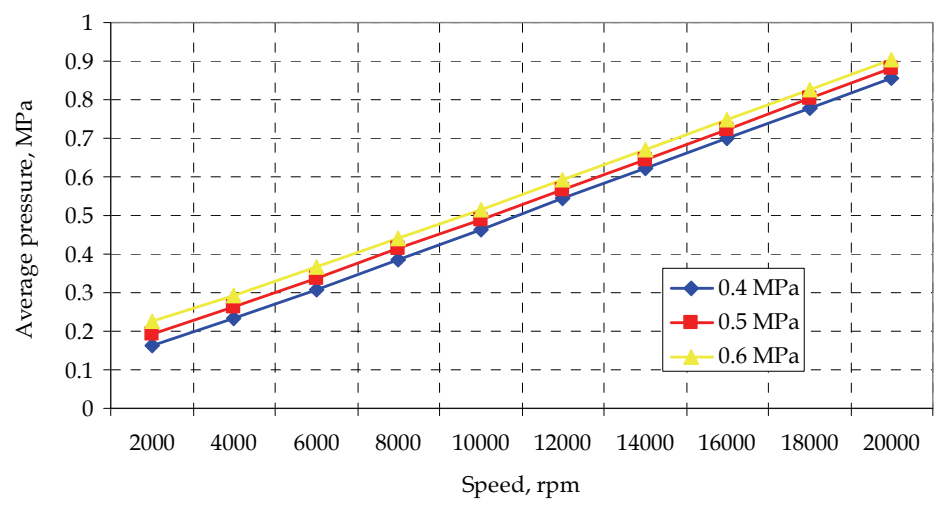

Fig. 36. Average pressure vs. speed for different supply pressures (five waves, minimum film thickness - 50 microns)

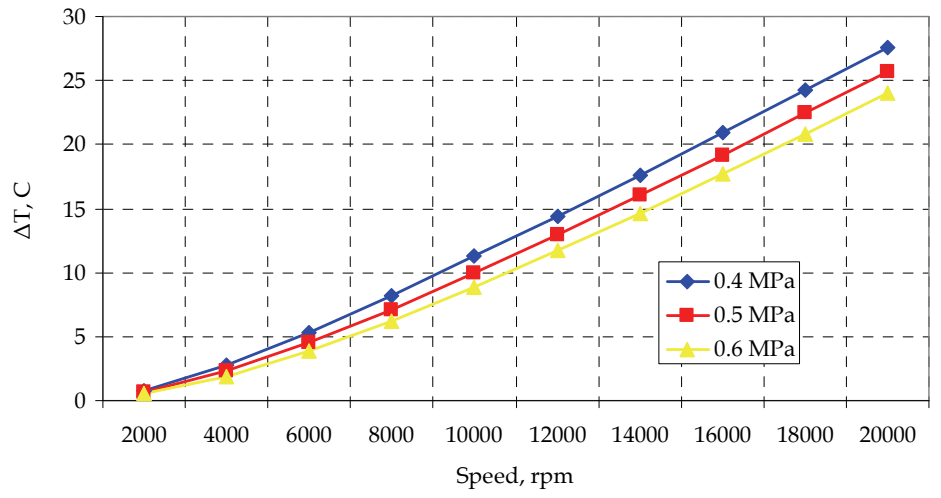

Fig. 37. The increase of the lubricant temperature vs. speed (five waves, minimum film thickness - 50 microns)

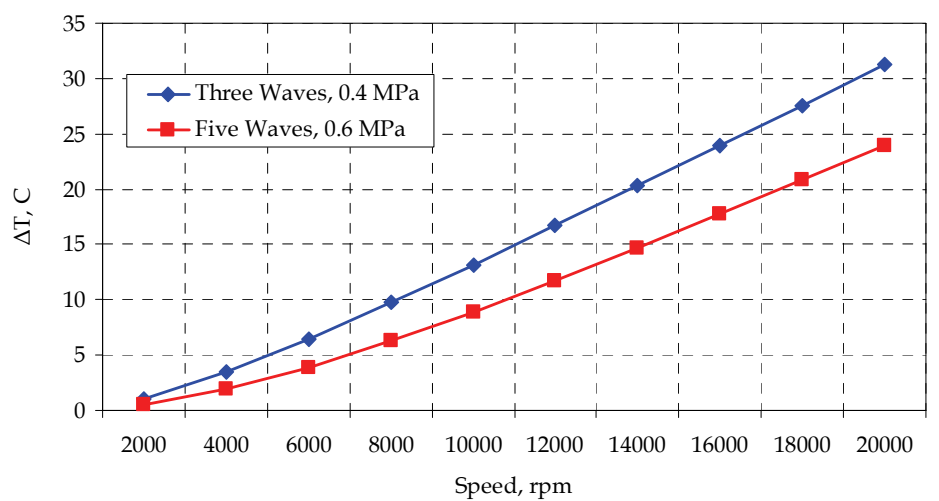

Fig. 38. Oil temperature increase vs. speed for different number of waves and supply pressures (minimum film thickness -50 microns) 
through the bearing can be obtained if the two effects are used together, as can be seen in Fig. 38. Fig. 38 shows that the increase of the oil temperature can be with up to $33 \%$ smaller for the bearing with five waves supplied with oil at $0.6 \mathrm{MPa}$ than for the bearing with three waves supplied with oil at $0.4 \mathrm{MPa}$.

\section{Concluding remarks}

A wave bearing can be a good alternative to any other type of fluid film bearing. Journal wave bearings offer increased dynamic and thermal stability compared to other types of journal fluid film bearings. Their actual load capacity could be even higher than the load capacity of the plain journal bearings due to the pumping effect of the wave profile that allows for a better cooling of the wave bearing. Besides the bearing clearance, the wave amplitude and the running parameters such as oil inlet pressure and temperature can be used to adjust the bearing performance to the needs of a specific application. The wave bearings are also simple and easy to manufacture. The wave journal bearing steady-state and dynamic performance can be precisely predicted with computer codes validated by experiments on dedicated test rigs.

Thrust wave bearings can be successfully used to carry axial loads or to axially position the shaft. Thrust wave bearings are also very simple compared to any other fluid film thrust bearings. They can have an individual oil supply system or can be lubricated with the oil that leaks laterally from a nearby journal bearing. Their performance can be also precisely predicted. The number of the waves, the wave amplitude, the minimum film thickness, the oil supply pressure and temperature can be used to maximize the bearing performance for a particular application.

\section{References}

Constantinescu, V. N., Nica, A., Pascovici, M. D., Ceptureanu, G. \& Nedelcu S. (1985). Sliding Bearings, Allerton Press, ISBN 0-89864-011-3, New York

Dimofte, F. (1995). Wave journal bearing with compressible lubricant - Part I : The wave bearing concept and a comparison to the plain circular bearing, Tribology Transactions, Vol. 38, No. 1, pp. 153-160

Dimofte, F. (1995). Wave journal bearing with compressible lubricant - Part II: A comparison of the wave bearing with a groove bearing and a lobe bearing, Tribology Transactions, Vol. 38, No. 2, pp. 364-372

Dimofte, F.; Proctor, M. P.; Fleming, D. P. \& Keith, T. G. Jr. (2000). Wave fluid film bearing tests for an aviation gearbox, Proceedings of the $8^{\text {th }}$ International Symposium on Transport Phenomena and Dynamics of Rotating Machinery, ISROMAC- 8, Honolulu, Hawaii, March 26-30, 2000, NASA/TM-2000-209766, January 2000

Lambrulescu M. I; Dimofte, F. \& Sawicki, J., T.(2003). Stability of a rotor supported by wave journal bearings as a function of oil temperature, Proceedings of $2^{\text {nd }}$ ISCORMA Meeting, Gdansk, Poland, August 4-8, 2003

Dimofte, F., Proctor, M.P., Fleming, D.P. \& Keith, T. G. (2004). Experimental investigations on the influence of oil inlet pressure on the stability of wave journal bearing, Proceedings of the 10th International Symposium on Transportation Phenomena and Dynamics of Rotating Machinery, Honolulu, Hawaii, ISROMAC 10-2004-146 
Dimofte, F.; Fleming, D. P.; Anderson, W. J. \& Klein, R. C. (2005). Test of a fluid film wave bearing at $350^{\circ} \mathrm{C}$ with liquid lubricants, STLE Tribology Transactions, Vol. 48, pp. 515-521

Dimofte, F. \& Ene, N.M. (2009). Comparison of the vibration/ noise of a geared transmission with shafts on fluid film bearings and on rolling element bearings, Proceedings of the 3rd International Conference Power Transmissions '09, 1-2 October, Chalkidiki, Greece

Ene, N. M; Dimofte, F. \& Keith Jr., T. G. (2008). A dynamic analysis of hydrodynamic wave journal bearings, STLE Tribology Transactions, Vol. 51, No. 1, pp. 82-91

Ene, N. M; Dimofte, F. \& Keith Jr., T. G. (2008). A stability analysis for a hydrodynamic three-wave journal bearing, Tribology International, Vol. 41, No. 5, pp. 434-442

Frêne, J. \& Constantinescu, V. N. (1975). Operating characteristics of journal bearings in the transition region, Proceedings of the 2nd Leeds - Lyon Symposium on Tribology, pp. 121124

Kirk, R. G. \& Gunter, E. J. (1976). Short bearing analysis applied to rotordynamics I: Theory, ASME Journal of Lubrication Technology, Vol. 98, pp. 47-56

Lund, J. W. (1987). Review of the concept of dynamic coefficients for fluid film journal bearings, ASME Journal of Tribology, Vol. 109, No. 37, pp. 37-41

Vijayaraghavan, D. \& Brewe \& D. E., (1992). Frequency effects on the stability of a journal bearing for periodic loading, ASME Journal of Tribology, Vol. 114, pp. 107-115 


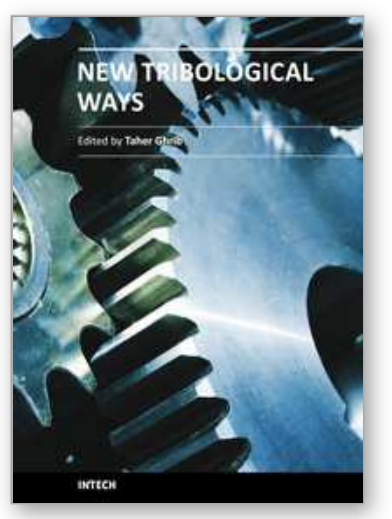

\author{
New Tribological Ways \\ Edited by Dr. Taher Ghrib
}

ISBN 978-953-307-206-7

Hard cover, 498 pages

Publisher InTech

Published online 26, April, 2011

Published in print edition April, 2011

This book aims to recapitulate old information's available and brings new information's that are with the fashion research on an atomic and nanometric scale in various fields by introducing several mathematical models to measure some parameters characterizing metals like the hydrodynamic elasticity coefficient, hardness, lubricant viscosity, viscosity coefficient, tensile strength .... It uses new measurement techniques very developed and nondestructive. Its principal distinctions of the other books, that it brings practical manners to model and to optimize the cutting process using various parameters and different techniques, namely, using water of high-velocity stream, tool with different form and radius, the cutting temperature effect, that can be measured with sufficient accuracy not only at a research lab and also with a theoretical forecast. This book aspire to minimize and eliminate the losses resulting from surfaces friction and wear which leads to a greater machining efficiency and to a better execution, fewer breakdowns and a significant saving. A great part is devoted to lubrication, of which the goal is to find the famous techniques using solid and liquid lubricant films applied for giving super low friction coefficients and improving the lubricant properties on surfaces.

\title{
How to reference
}

In order to correctly reference this scholarly work, feel free to copy and paste the following:

Florin Dimofte, Nicoleta M. Ene and Abdollah A. Afjeh (2011). No Conventional Fluid Film Bearings with Waved Surface, New Tribological Ways, Dr. Taher Ghrib (Ed.), ISBN: 978-953-307-206-7, InTech, Available from: http://www.intechopen.com/books/new-tribological-ways/no-conventional-fluid-film-bearings-with-wavedsurface

\section{INTECH}

open science | open minds

\section{InTech Europe}

University Campus STeP Ri

Slavka Krautzeka 83/A

51000 Rijeka, Croatia

Phone: +385 (51) 770447

Fax: +385 (51) 686166

www.intechopen.com

\section{InTech China}

Unit 405, Office Block, Hotel Equatorial Shanghai

No.65, Yan An Road (West), Shanghai, 200040, China 中国上海市延安西路65号上海国际贵都大饭店办公楼405单元

Phone: +86-21-62489820

Fax: +86-21-62489821 
(C) 2011 The Author(s). Licensee IntechOpen. This chapter is distributed under the terms of the Creative Commons Attribution-NonCommercialShareAlike-3.0 License, which permits use, distribution and reproduction for non-commercial purposes, provided the original is properly cited and derivative works building on this content are distributed under the same license. 